\title{
LÍMITE DE LA TÉCHNE Y VIRTUD DEL DIÁLOGO SEGÚN Platón
}

\author{
Cristián De Bravo Delorme ${ }^{1}$
}

Resumen: El siguiente artículo parte reconociendo el carácter protector de la téchne y sus momentos constitutivos. De acuerdo a esta determinación es posible advertir el límite de la téchne a partir de la cuestión socrática de la virtud. La virtud, en la medida que no es un asunto análogo a los objetos de la téchne, precisa de un especial acceso. Desde la constatación del diálogo como el único modo de conocer la virtud, se pone de relieve su sentido comunitario y el carácter del examen socrático. En el diálogo socrático se anuncia, así, que la virtud no es nunca algo técnicamente clausurado ni epistémicamente conceptualizado, sino el mayor bien humano que se cumple en su aproximación a través del examen conjunto de la propia vida.

Palabras clave: Conocimiento. Virtud. Diálogo. Necesidad.

\section{INTRODUCCIÓN}

Según Aristóteles, Sócrates, al preguntar "qué es", habría tratado de

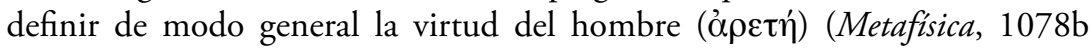
17-30). Por lo tanto, Sócrates habría supuesto que era posible una ciencia

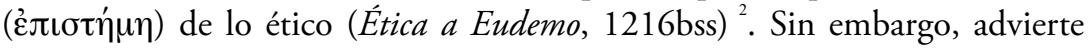

${ }^{1}$ Investigador y asistente honorario del Departamento de Estética e Historia de la Filosofía de la Universidad de Sevilla, Sevilla - Espańa. (D) http://orcid.org/0000-0002-6363-9165 E-mail: debravo.cristian@gmail.com

Este trabajo forma parte de una investigación financiada por el Programa Nacional de Becas de la República Eslovaca.

2 Aristóteles se refiere expresamente a Sócrates el viejo (ó $\left.\pi \rho \varepsilon \sigma \beta \tau^{\prime} \eta \varsigma\right)$ y, por lo tanto, al Sócrates histórico. En la siguiente consideración no haremos una diferencia entre este Sócrates histórico y el de los diálogos platónicos, pues ambos coinciden en el modo de investigar criticado por Aristóteles. Por otra parte, al realizar esta crítica Aristóteles tiene a la vista su propia distinción entre los conocimientos y, por lo tanto, el ámbito respectivo a cada conocimiento. En el libro VI de la Ética a Nicómaco, Aristóteles considera la técnica ( $\tau \dot{\varepsilon} \chi \nu \eta)$ como el saber productivo, la ciencia ( $\dot{\varepsilon} \iota \sigma \tau \eta \dot{\mu} \eta)$ como el saber

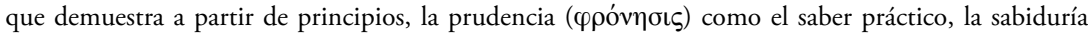

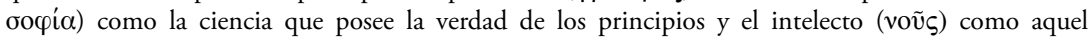
conocimiento inmediato de los principios.

http://dx.doi.org/10.1590/0101-3173.2019.v42n4.02.p9 
Aristóteles, al preguntar Sócrates de manera teórica por una cuestión de orden práctico no habría distinguido entre ciencia y prudencia. Sócrates habría "teorizado" sobre la virtud, pero no habría aclarado cómo ni de dónde se genera. Para algunos comentaristas esa moral de corte racional estaría testificada en el Gorgias (468c, 488a) y en el Protágoras (351b-358e), donde aparentemente sería suficiente el poder intelectual a la hora de actuar ${ }^{3}$. Terence Irwin, más aún, al referirse a la ética socrática habla de un "conocimiento instrumental" de la virtud (craft-knowledge). ${ }^{4}$ De este modo, Sócrates no sólo habría sido el primero en considerar la suficiencia intelectual de la conducta humana, sino que, además, habría sido un pensador técnico.

Lo que se suele denominar como "craft-analogy" (PARRY, 1996;

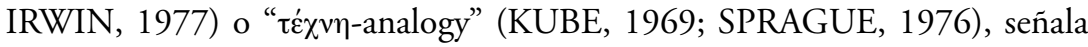
precisamente el nudo del problema. Según esta analogía, Sócrates al preguntar por la virtud humana toma como orientación el modo de conocer de la

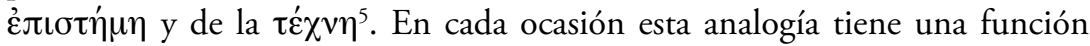
determinada $^{6}$. Así, por ejemplo, Sócrates al preguntarle a Critias por el "producto" ("̌ $\rho \gamma o v)$ de la moderación ( $\sigma \omega \varphi \rho o \sigma u ́ v \eta)$, pone como ejemplo a la salud como "producto" de la medicina" y al edificio como "producto" de la arquitectura (Cármides, 165c-e). Asimismo, Sócrates utiliza la misma analogía con Téages (123b-124c), quien es llevado a clarificar su comprensión del saber que desea en comparación con el pilotaje y la conducción de caballos. La analogía también tiene una clara función con Hipócrates (Protágoras, 311b-313a), quien es exhortado a responder por aquello que desea aprender de Protágoras bajo la orientación de lo que enseñan médicos y escultores. De igual modo Sócrates usa esta analogía con Ión (531b-533d) en orden a justificar su propia capacidad y con Gorgias (449a-454b) para acreditar su pretendido saber. Por lo tanto, la medicina, la escultura, el pilotaje, la arquitectura entre otros saberes, servirían como ejemplos de conocimiento para aprender qué es la virtud y cómo es posible. Por eso Sócrates puede

${ }^{3}$ Para una discusión y evaluación de esta opinión, sus distintas variaciones y problemas véase Vlastos (1957, p. 226-232), Nehamas (1987, p. 275-316), Gould (1987, p. 265-279), Kahn (1996, p. 224233), Rickless (1998, p. 355-367), Segvic (2000, p. 1-45), Evans (2010, p. 6-33), Hardy (2014, p. 141-170).

4 "Sócrates tiene buenas razones para pensar que la virtud real es una técnica instrumental (craft); porque una técnica instrumental satisface alguna de las demandas básicas de la virtud y el conocimiento moral." (IRWIN, 1977, p. 75).

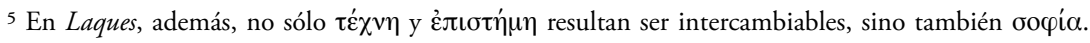
Véase, por ejemplo, 193 b y $194 \mathrm{e}$.

${ }^{6}$ Para una consideración de las distintas funciones de la analogía, véase Roochnik (1986, p. 295-310). 
advertirle a Melesias, en el diálogo Laques, que para poder juzgar bien respecto

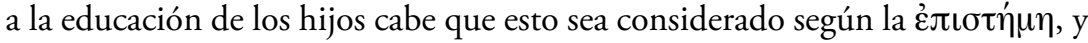
tras el asentimiento de aquel dice: "Así pues, también ahora toca examinar esto

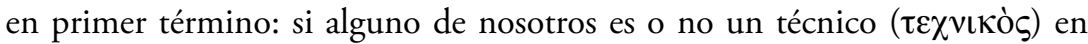
el tema que consideramos." $(184 \mathrm{e})^{7}$. Tales advertencias serían un testimonio

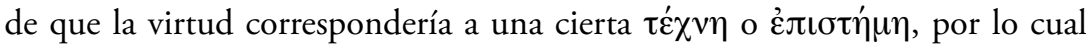
no sólo la crítica de Aristóteles estaría bien fundada, sino, además, la opinión según la cual Sócrates sostendría un racionalismo moral e, incluso, una moral instrumental.

El siguiente artículo pretende esclarecer, a la luz de la Apología y a través de ciertos momentos extraídos de algunos diálogos aporéticos ${ }^{8}$, el significado de la $\tau \varepsilon^{\prime} \chi v \eta$ y en qué sentido es posible hablar de un conocimiento de la virtud. El artículo parte de algunas indicaciones generales y específicas sobre la $\tau \dot{\varepsilon} \chi v \eta$ que ofrecerán una primera aproximación a la dimensión del saber en tanto tal (2). Posteriormente se expondrán ciertos pasajes para poner de relieve tanto el alcance de la $\tau \dot{\varepsilon} \chi v \eta$ (3) como su límite respecto a la cuestión socrática (4). A partir de este límite indicado será posible considerar el sentido del acceso a la virtud (5). Por último, se hará una consideración final (6).

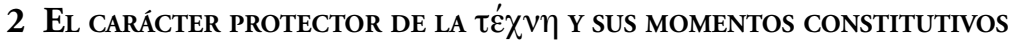

Según la moderna filología, la palabra $\tau \dot{\chi} \chi v \eta$ se relaciona con $\tau \dot{\varepsilon} \kappa \tau \omega v$ (carpintero) y proviene de la raíz indoeuropea teǩp-, que se conserva en la palabra griega $\tau \tilde{\imath} \chi 0 \varsigma$ (muralla, fortificación, fortaleza) y en la latina tegere (proteger, cubrir e incluso esconder y disfrazar). En castellano esta misma raíz se mantiene, por ejemplo, en la palabra "techo", del latín tectum. Según Pokorny (1959, p. 1058), la palabra $\tau \dot{\varepsilon} \chi v \eta$ originalmente remite al acto de entrelazar, juntar y armar algo a partir de la madera. Ahora bien, quién

${ }^{7}$ Con la excepción de que se diga lo contrario, uso, salvo con leves modificaciones, las traducciones de los dos volúmenes Diálogos de Platón, Gredos, Madrid, 2011.

${ }^{8}$ No es pertinente aquí un juicio acerca de la datación de composición de los diálogos, según la cual se dividirían en "tempranos" o "aporéticos", "intermedios" y "tardíos". Pese a que entre muchos comentaristas y estudiosos, las evidencias literarias, lingüísticas y estilísticas apuntarían a establecer una cronología verosímil de los diálogos, hace ya un tiempo considerable que ha sido puesta en cuestión esta datación, la cual, por lo demás, supone en muchos casos el supuesto de una cierta "evolución" intelectual y doctrinal del pensamiento platónico. (THESLEFF, 1989, p. 1-26; BRANDWOOD, 1990; HOWLAND, 1991, p. 189-214; POSTER, 1998, p. 282-298; ALTMAN, 2010, p. 18-51). En este trabajo los diálogos "aporéticos" sólo son así designados atendiendo únicamente al sentido problemático de la cuestión de la virtud. 
construye una casa, quién sana a un enfermo, quien toca un instrumento musical, tiene $\tau \varepsilon^{\prime} \chi v \eta$, en suma, porque ve lo que aún no está presente, porque la $\tau \dot{\chi} \chi v \eta$ es, según Heidegger (1983, p. 168), "el inicial y constante ver más allá de lo que ya está delante”. Esa visión, en suma, proviene del $\lambda$ ó $\gamma$ os. De ahí que Aristóteles en el libro A de la Metafísica diga simplemente que "a la humana

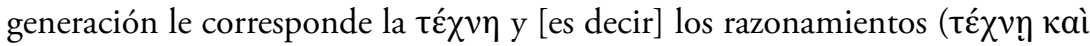

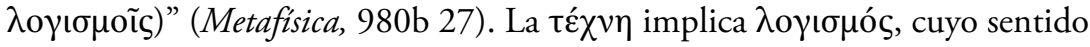
aquí no se refiere tanto a un razonamiento meramente teórico como a un prever y, por lo tanto, calcular, sopesar y ponderar. Martha Nussbaum describe así lo principal de la $\tau \varepsilon ́ \chi v \eta:$

La téchne es, pues, una aplicación deliberada de la inteligencia humana a alguna parte del mundo que proporciona cierto dominio sobre la tyche; se relaciona con la satisfacción de las necesidades y con la predicción y el dominio de contingencias futuras. Por lo general, a la persona que vive según la téchne, las experiencias nuevas no la cogen por sorpresa o sin recursos. Esa persona posee cierto tipo de aprehensión sistemática de las cosas, un modo de organizarlas, que hace que se encuentre bien preparada en las situaciones nuevas, a salvo de la ciega dependencia del acontecer. (NUSSBAUM, 1995, p. 143).

Resulta muy significativa la relación que Nussbaum establece entre la

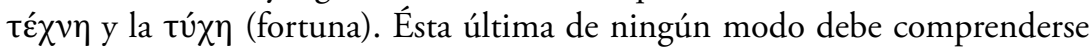
como una especie de quebrantamiento del orden causal de las cosas. Más bien,

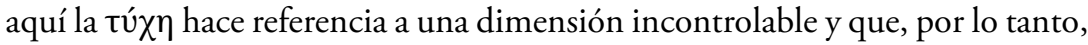
expone al hombre a la intemperie e inhospitalidad de lo que simplemente pasa.

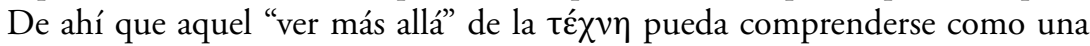
anticipación a la imprevista fuerza de las cosas, pero que, ciertamente, tiene un límite, ya que su transgresión puede provocar la ruina. Con todo, la té $\chi v \eta$ toma su auténtica forma en aquella disposición por la cual es posible auxiliar al hombre de aquello que proviene de la suerte y de los peligros que lo amenazan. Por ello en el diálogo Eutidemo, al referirse Sócrates a la бopía como aquella disposición que destaca la maestría en la ejecución de la flauta, en la estrategia, en el pilotaje, en la medicina, etc., le dice al joven Clinias: "Estando presente la

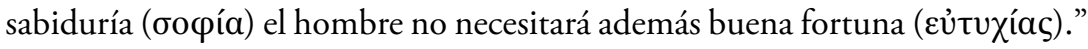

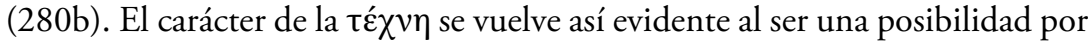
la cual el hombre se anticipa y se protege de las adversidades del acontecer. En

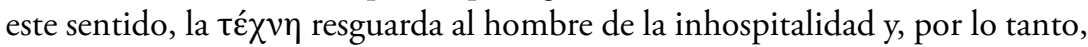
procura un techo, un albergue a la existencia humana. 


\section{El ALCANCE DE LA Té $\chi v \eta$}

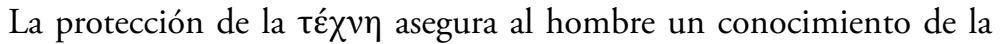
causa de las cosas. En efecto, esta seguridad radica en conocer el "por qué". Según Aristóteles, este conocimiento marca la diferencia entre la mera experiencia o habilidad y el auténtico saber, pues, pese a que en ocasiones resulte la $\tau \varepsilon ́ \chi v \eta$ inferior a la experiencia, a saber, en el caso de contar sólo con la mera "teoría" frente a la práctica que comporta aquella, la té $\chi \nu \eta$ se presenta ciertamente superior, al iluminar toda una dimensión de eventos a partir de sus causas y a la que la experiencia no puede acceder por enfocar de manera muy restringida lo que en cada caso ocurre (Metafísica, 981a13-981b9).

A la vista de esta superioridad, Sócrates puede declarar entonces que "a cada té $\chi v \eta$ le ha sido concedida por la divinidad la facultad de entender en un dominio concreto" (Ion, 537c), con lo cual cada obrero y artesano tiene a la vista su propia obra ("̌́pүov) (Gorgias, 503e). Según esto, se destaca que cada $\tau \varepsilon ́ \chi v \eta$ está referida a un específico ámbito de cosas y que esta delimitación del campo de ejecución se revela en un determinado fin que en cada caso se

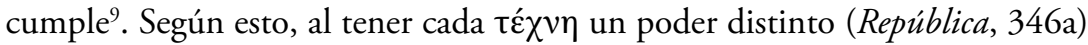
es beneficiosa y útil a su modo (República, 346c), lo que convierte a cada

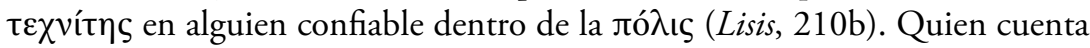
con una $\tau \varepsilon ́ \chi v \eta$, además, no sólo beneficia con su respectiva obra, sino que, además, puede enseñar su saber. Por ello, el hombre con té $\chi \nu \eta$ resulta ser un maestro y un buen consejero (Protágoras, 319b-e).

A partir de lo anterior es posible reconocer, al menos, 6 momentos

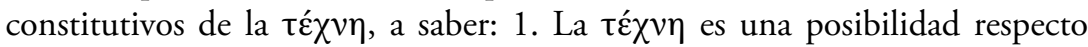

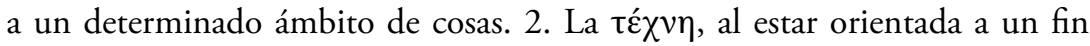
específico, ejecuta una determinada obra. 3. La té $\chi \nu \eta$ es una posibilidad estimada dentro de la comunidad por el beneficio y la utilidad que procura. 4. La $\tau \varepsilon ́ \chi v \eta$ es una posibilidad que acredita confianza y autoridad dentro de

\footnotetext{
${ }^{9}$ Cabe tener presente que esta determinación del ámbito y de la obra correspondiente a cada té $\chi v \eta$ puede caer en el equívoco en el momento de descubrir modos distintos de referirse al mismo ámbito y, por consiguiente, modos diferentes de ejecutar la obra correspondiente. Así se revela en el Gorgias (462b-466a) que tanto la retórica como la sofística constituyen su referencia al mismo ámbito que la justicia y la política, a saber, el alma. De igual modo, la cosmética y la culinaria se refieren a lo mismo que el deporte y la medicina, esto es, el cuerpo. De ahí surge el problema de las diferentes intenciones con respecto a la obra que se cumple. La clarificación de este equívoco, sin embargo, radicará en la auténtica orientación de cada intención ejecutiva, lo cual revelará, en último término, si cada una es

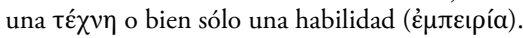




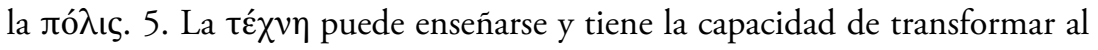
otro en un experto. 6. La $\tau \varepsilon ́ \chi \nu \eta$ procura familiaridad con las cosas que trata.

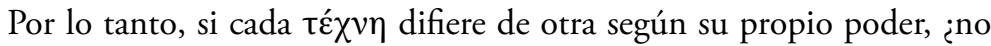
resulta comprensible deducir que a la virtud le corresponde una té $\chi \nu \eta$ ? ¿No parece juicioso pensar que, así como es posible aprender determinados oficios como la carpintería y la medicina, resulta también posible aprender la virtud mediante una determinada instrucción? Bajo esta sugerente analogía Sócrates en la Apología relata a sus conciudadanos un encuentro con Calias, quien había pagado por su instrucción grandes sumas de dinero a los sofistas: ${ }^{10}$

Calias - le dije -, si tus dos hijos fueran potros o becerros, tendríamos que

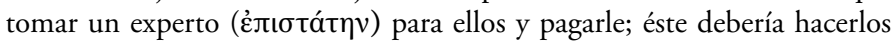
aptos y buenos con respecto a su propia virtud, y sería un conocedor de los caballos o un agricultor. Pero, puesto que son hombres, ¿qué cuidador

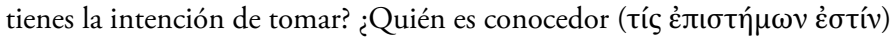
de esta clase de perfección, de la humana y política? (Apología. 20a-b).

Sócrates, según sus palabras, pareciera sugerir que, tal como en el caso de ciertos animales, a la vida humana le correspondería un cuidado semejante, en orden a fomentar y modelar su propio ser. De hecho, según esta misma analogía y bajo la necesidad de resolver sobre la educación de los hijos de Lisimaco y Melesias, Sócrates exhorta en el Laques: "Entonces hay que buscar

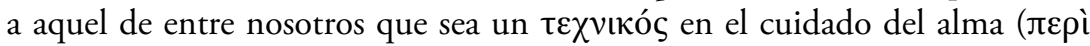

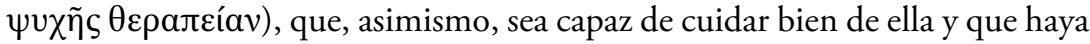

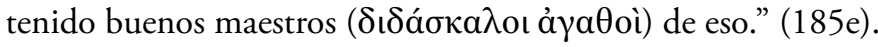

No obstante, pese a que la analogía de la té $\chi v \eta$ y la virtud de pábulo a pensar en una técnica o ciencia de la virtud, sólo cabe analizar el testimonio de los textos. No es posible aquí una interpretación detallada de los diálogos, para lo cual cabe advertir con mucho cuidado el contexto dentro del cual surge cada problema. Sin embargo, bastarán ciertas indicaciones para percatarnos del alcance significativo del asunto en cuestión. Lo importante es fijarse en el énfasis y en la acentuación de Sócrates sobre aquello que constituye el núcleo del problema de la virtud.

${ }^{10}$ Cabe notar la referencia a Calias y a su instrucción bajo un tono ciertamente irónico. En efecto, según lo que seńala Debra Nails (2002, p. 68), Calias de Alopece es caracterizado como una grotesca figura, controlado por sus pasiones, notablemente lujurioso y codicioso. 


\section{El LÍMITE DE LA Té $\chi v \eta$}

En la Apología se expone el juicio a Sócrates, quien ha sido acusado de corromper a la juventud y de crear otros dioses. En el primer discurso a sus conciudadanos, Sócrates relata la historia de la visita a Delfos de su amigo de juventud Querefonte, quien tuvo la osadía de preguntar al oráculo si había entre los hombres alguien más sabio que Sócrates. La respuesta del oráculo revela una monstruosa verdad. En efecto, pese a saberse ignorante, Sócrates es reconocido por el dios como el más sabio entre los hombres. Perplejo durante mucho tiempo por esta situación confiesa Sócrates que decidió con turbación ( $\mu$ ó ıৎ) buscar aclarar el oráculo e incluso refutar la palabra del dios, lo cual, por de pronto, debe hacernos advertir el exceso de su propia tarea ${ }^{11}$. Así, Sócrates recorrió toda la jó $\lambda$ ıৎ tras alguien que se mostrara como sabio con el fin de exponer el error del oráculo. Sócrates dice a sus conciudadanos:

Me encaminé por último hacia los técnicos manuales. Tenía presente

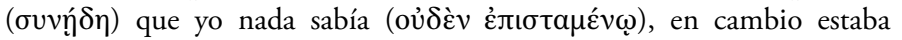
seguro que encontraría a éstos con muchos y hermosos conocimientos

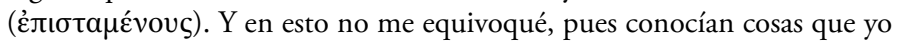
no conocía y, en ello, eran más sabios que yo. Pero, atenienses, me pareció también que los buenos obreros de la ciudad incurrían en el mismo error

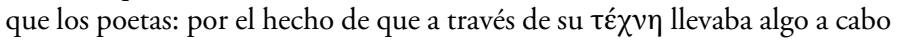
hermosamente, cada uno de ellos estimaba que era muy sabio también respecto a los demás asuntos, incluso respecto a los asuntos más grandes, y esa disonancia hacía oscurecer su sabiduría. (22 c-e).

La expresa diferencia que Sócrates hace entre la lucidez de su propia

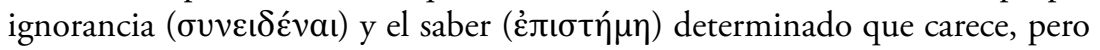
que reconoce en otros, resulta ser una señal muy significativa para nuestra consideración. Pues, aunque Sócrates en los diálogos al referirse a los diversos

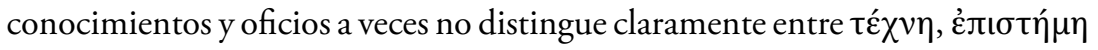
у бофía, se reserva para su propia disposición esta conciencia y, en relación a esta conciencia, declara tener un conocimiento correspondiente. Así, por ejemplo, Sócrates se refiere al sentido del oráculo de este modo: "Es el más sabio, el que, de entre vosotros, hombres, conoce (ع́ $\gamma v \omega \kappa \varepsilon v)$, como Sócrates, que en verdad es digno de nada respecto a la sabiduría." (23b). Por lo tanto, cabe advertir esta primera indicación respecto al saber mismo de Sócrates, que

${ }^{11}$ Respecto al problema de la piedad o impiedad socrática que constituye su propia disposición filosófica véase González (2007, p. 33-58). 
él mismo comprende como un conocimiento ( $\gamma \nu \omega ́ \sigma ı \varsigma)$ fundado en una cierta conciencia o, mejor dicho, en una cierta autotransparencia ${ }^{12}$.

Ante esta distinción, entonces, cabe advertir otro momento muy importante. Sócrates en su búsqueda se encuentra con los llamados y

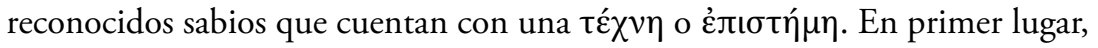
los políticos y los poetas. Tras examinar a estos, va con aquellos que producen obras beneficiosas y útiles para la comunidad y se percata que incurren en el mismo error que los anteriores. Aquellos sabios que se muestran ciertamente

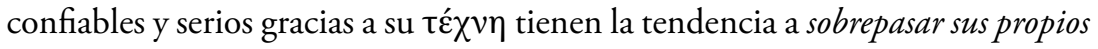
límites y estimarse no sólo sabios dentro de lo suyo propio, sino incluso muy sabios respecto a otros asuntos $y$, ante todo, sobre los más grandes asuntos. Contando con una determinada té $\chi \nu \eta$, pero creyendo saber de otros y más grandes asuntos, estos sabios caen en el error de ir más allá de lo que saben. De este modo Sócrates advierte que quien sabe obrar bien dentro de su propio ámbito tiende a olvidar su ignorancia al exceder los límites que determinan su $\tau \varepsilon ́ \chi v \eta$. Ignorando el alcance de su saber, pero creyendo conocer más allá, extralimitan los sabios su propia dimensión. ¿Cuál es aquel límite que toda $\tau \varepsilon ́ \chi v \eta$ resulta exceder? Sócrates relata lo siguiente:

No iba a donde no fuese útil para vosotros o para mí, sino que me remitía a cada uno en privado llevando a cabo bien lo que yo digo ser el más grande beneficio; yendo aquí y allí, intentando persuadir a cada uno de

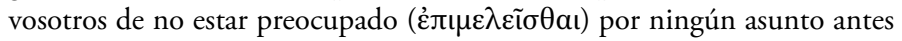

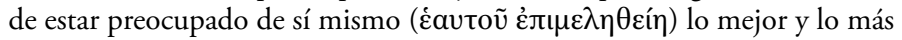
prudentemente posible, ni que tampoco se preocupara de sus asuntos en la

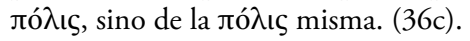

A toda $\tau \varepsilon ́ \chi v \eta$, por cierto, le corresponde su delimitado ámbito de referencia que le garantiza su auténtico poder de ejecución. Pero ocurre que aquel que tiene té $\chi \nu \eta$, al tratar confiadamente con las cosas y al estar familiarizado con su ámbito de ejecución, supone que dentro de esta confianza y familiaridad hay un "resto" que parece pertenecer a su dominio, pero que, sin percatarse, "excede" sus conocimientos. Este "exceso", de hecho, parece lo más familiar y cercano, más incluso que aquellas cosas con las cuales la té $\chi \nu \eta$ trata y ejerce su dominio. Sin embargo, este "resto" resulta encontrarse a una distancia que cotidianamente se mantiene oculta y que, al momento de mostrarse bajo

${ }^{12}$ Charles Griswold (1986, p. 261, n. 23) dice al respecto lo siguiente: "Sócrates, siguiendo al oráculo de Delfos, habla de la necesidad de 'gignoskein' a sí mismo (no epistasthai) [...] el autoconocimiento 'gnóstico' no es epistémico." 
el examen de Sócrates, revela toda su inquietante urgencia y necesidad. Este "exceso" o "resto" que parece pertenecer a la familiaridad del ámbito de la $\tau \varepsilon ́ \chi v \eta$ y que parece encontrarse bajo el dominio confiado de su conocimiento, lo nombra Sócrates como "sí mismo", el cual se retira de las preocupaciones de la $\tau \varepsilon ́ \chi v \eta$. Más exactamente, lo que se retira de las preocupaciones que cada

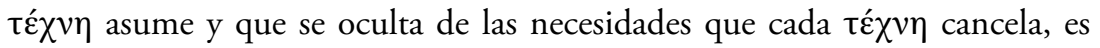

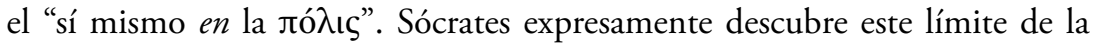
$\tau \varepsilon ́ \chi \nu \eta$ bajo un evidente contraste. Los sabios a los que examinaba Sócrates se preocupaban de muchas cosas, a saber, el negocio ( $\chi \rho \eta \mu \alpha \tau ı \sigma o ́ s)$, el cuidado

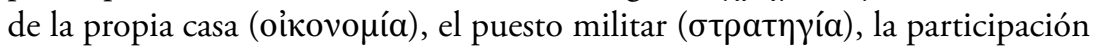

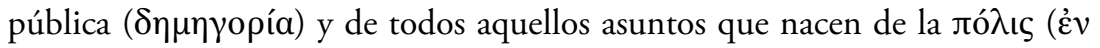
$\tau \tilde{\eta} \pi o ́ \lambda \varepsilon \iota ~ \gamma \iota \gamma \nu o \mu \varepsilon ́ v \omega v)$ (36b), mas no reparaban en "sí mismos". El principal

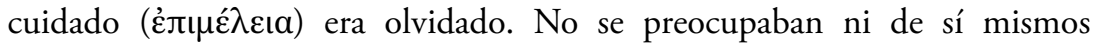

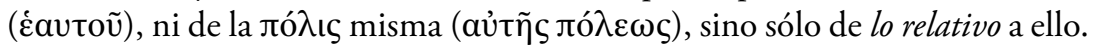
Por ello, debemos notar muy cuidadosamente que aquel "resto" y "exceso" que sale a relucir en el discurso de Sócrates no es simplemente la individualidad del sujeto frente al mundo, sino, más bien, el "ser mismo en la лó $\lambda ı$ ".

A pesar de ello, a cada sabio le parecía tenerse a sí mismo bajo cuidado

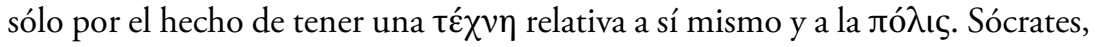
incluso, afirma que ciertos hombres con $\tau \varepsilon ́ \chi v \eta$ pretenden conocer la virtud y enseñarla (19e-20b). Entre esos conocedores se encontraba un tal Eveno de Paros. Sobre esto Sócrates afirma no sin ironía: "Y yo consideré bendito a Eveno, si verdaderamente tiene la virtud y la enseña tan armoniosamente. En cuanto a mí, presumiría y me jactaría si supiera estas cosas, pero no las sé, atenienses." (20b-c). Es más, Sócrates afirma que quien pretenda un conocimiento así es probable que sea un sabio respecto a una sabiduría mayor que la propia de un hombre (20e).

Por lo tanto, debemos percatarnos de 6 momentos que se descubren aquí y que corresponden a la contraparte de los momentos constitutivos de la $\tau \varepsilon ́ \chi v \eta$. En efecto, lo que Sócrates pone a la vista respecto a este "sí mismo" es lo siguiente: 1 . No parece corresponder a ningún asunto de la té $\chi v \eta$. 2. No es

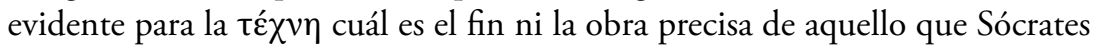
revela. 3. No resulta ser algo advertido ni tampoco parece su preocupación ser necesaria ni útil. 4. Se toma como algo mínimo, a tal punto que parece ser por todos conocido y obvio ${ }^{13} .5$. Pese a que sofistas y oradores declaren conocer

\footnotetext{
${ }^{13}$ Véase, por ejemplo, cómo Eutifrón, al ser interrogado por aquel saber de eso que, en su caso resulta ser la piedad, responde que no es sino una nadería (Eutifrón, 3e), tal como no es difícil para Laques
} 
y enseñar la virtud, no parece que sea ni conocible ni enseñable. 6. Aunque parece ser lo más cercano en cada ocupación de la té $\chi \vee \eta$, muestra su distancia y se presenta completamente extraño a toda familiaridad.

A la vista de lo anterior el próximo paso será considerar cómo se revela esa "mismidad" a la cual alude Sócrates y que parece no ser dominada por ninguna $\tau \varepsilon ́ \chi v \eta$ ni parece corresponder a ningún ámbito familiar del conocimiento técnico o epistémico.

\section{LA VIRTUd DEL DiálOgo}

Hemos considerado de una manera esquemática en qué sentido la $\tau \varepsilon ́ \chi \nu \eta$ como posibilidad propiamente humana no sólo protege al hombre de las vicisitudes de la fortuna, sino que, gracias a su propio carácter, puede abrir diferentes dominios y asegurar la realización y cumplimiento de determinados beneficios para el hombre. Sin embargo, en el momento en que Sócrates

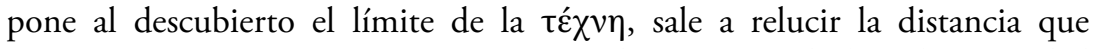
caracteriza a eso que precisamente no puede ser sometido bajo la autoridad de ninguna $\tau \varepsilon ́ \chi v \eta$. No obstante, como dice Gregory Vlastos (1995, p. 8), Sócrates "tiene un evangelio, una gran verdad que enseñar: nuestra alma es la única cosa en nosotros digna de salvarse y hay sólo un modo de hacerlo: adquirir conocimiento”. Sin embargo, ¿no declara Sócrates, públicamente en la Apología y privadamente a través de la refutación, no saber sobre lo que pregunta? Sócrates, por ejemplo, sin un rastro de disimulo y sorprendido por la sospecha de Critias, le dice:

¿Cómo puedes suponer algo así? Piensas que, si tanto te refuto, yo lo hago por un motivo distinto a aquel que me lleva a investigarme a mí mismo y a lo que digo, por temor, tal vez a que se me oculte que pienso que sé algo, sin saberlo ( $\delta \dot{\varepsilon} \mu \eta \tilde{)}) .(166 c-d)$.

Según estas palabras, Critias habría estado suponiendo cierta mala fe en Sócrates, al pensar que, simulando no saber acerca de lo que preguntaba, sólo lo refutaba por motivos meramente erísticos. Sócrates, sin embargo, no duda en confesar lo contrario. La refutación no sólo consiste en probar la inconsistencia de la opinión del interlocutor, sino, antes bien, en revelar la ảropía misma del

responder sobre la valentía (Laques, 190e). 
asunto $^{14}$. De ahí que algunos comentaristas hayan reconocido únicamente el carácter destructivo de la refutación (BENSON, 1995, p. 45-112). Por lo tanto, ¿en qué sentido es posible afirmar que Sócrates apela a un conocimiento de la virtud? Según Paul Woodruff (1986, p. 30) y otros, pese a su carácter negativo, la refutación no buscaría sino definiciones (FINE, 1992, p. 202 ss; IRWIN, 1995, p. 21ss; FORSTER, 2006, p. 1-47). Vlastos (1994, p. 1-29) piensa, por su parte, que Sócrates al refutar rescataría un conocimiento "salvífico" a partir de la deducción de creencias verdaderas o, al menos, verosímiles y opuestas a las aseveraciones refutadas. ${ }^{15}$ Bajo el mismo enfoque "constructivista", aunque corrigiendo la anterior convicción, Thomas Brickhouse y Nicholas Smith afirman que sólo la reiterada experiencia refutatoria, que le permite a Sócrates examinar un conjunto de creencias diferentes en orden a ponderar su consistencia, "puede generar resultados constructivos, es decir, razones para aceptar proposiciones y rechazar otras" (BRICKHOUSE; SMITH 2000, p. 88). Cuando nos aproximamos a ciertos diálogos la evidencia textual pareciera hablar a favor de estas opiniones. Pero esto es sólo una apariencia. Por de pronto, si bien el repetido examen y la refutación pertenecen al núcleo mismo del diálogo, de ninguna manera constituyen un medio pedagógico o una fase propedéutica para alcanzar ciertas definiciones, un conjunto de verdades o creencias morales. En contraste a la pretensión de los oradores y sofistas y de todos aquellos que, contando con una determinada $\tau \varepsilon ́ \chi \nu \eta$, pretenden conocer la virtud e incluso enseñarla, Sócrates confiesa a sus conciudadanos lo siguiente:

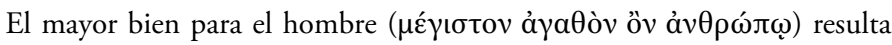

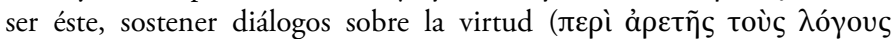

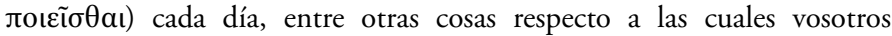
me habéis escuchado dialogar y examinarme a mí mismo y a los otros

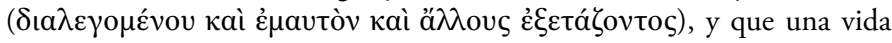
sin examen no merece ser vivida por una vida humana. (38a).

¿Cómo puede el mayor bien del hombre consistir en conversar acerca de la virtud? ¿ No debería radicar el bien en su posesión? Extraña afirmación

\footnotetext{
${ }^{14}$ Cf. Menón, 80c: Sócrates le dice a Menón: "En efecto, no es que yo sabiendo encontrar una salida ponga obstáculos a los otros, sino que estando yo del todo obstaculizado, también dejo a los demás sin salida." (La traducción es mía).

${ }^{15}$ Cabe tener presente que Vlastos considera el rendimiento de la refutación socrática principalmente en el Gorgias, en la medida que aquí Sócrates defiende ciertas conclusiones, lo cual, por lo demás, demostraría las limitaciones de lo que en aquel diálogo Sócrates hace (GONZÁLEZ, 1998, p. 284, n. 52).
} 
la de Sócrates, ciertamente, sobre todo porque no pocos lo habían soportado escuchar hablar de zapateros, cardadores, cocineros y médicos (Gorgias, 491a). No obstante, como el mismo Alcibíades confiesa ${ }^{16}$, en lo más ordinario reluce lo extraordinario del diálogo socrático. En el dar y recibir $\lambda$ óyos Sócrates expone al otro ante sí mismo y, así, en el constante desarrollo y maduración de la indagación conjunta la vida se cumple. Es precisamente porque la vida humana es finita y nunca concluida en su ser, que la virtud puede consistir en el dialogar como una aproximación constante a sí misma. En este punto no puede ser exagerado enfatizar el rasgo comunitario de la investigación socrática, pues el diálogo se alza no como un mero recurso, sino como un modo de ser, por el cual la cooperación dialógica resulta imitar la propia operación de la vida. En ese sentido puede Sócrates decirle a Protágoras:

Protágoras, no creas que yo dialogo contigo con otra intención que la de examinar esas cosas de las que yo no conozco solución. Pues creo que acertaba Homero al decir lo que: "Marchando juntos, el uno alcanza a ver antes que el otro." Porque reunidos somos los hombres, de algún modo, más hábiles para cualquier trabajo, palabra o plan. (Protágoras, 348c-d).

Son muchos los ejemplos donde Sócrates expresa la necesidad de investigar conjuntamente aquello que se encuentra puesto en cuestión. Así, en el Cármides, Sócrates, suponiéndole Critias un conocimiento de la cuestión, le dice:

Pero tú, Critias, te pones ante mí como si yo afirmase que sé aquello por lo que pregunto, y que, tan pronto como lo quisiera, estaría de acuerdo

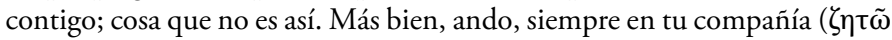

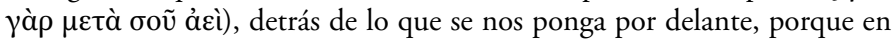
verdad que yo mismo no lo sé. (165b-c).

\footnotetext{
16 "Porque, efectivamente [...] sus discursos son muy semejantes a los silenos que se abren. Pues si uno se decidiera a oír los discursos de Sócrates, al principio podrían parecer totalmente ridículos. ¡Tales son las palabras y expresiones con que están revestidos por fuera, la piel, por así decir, de un sátiro insolente! Habla, en efecto, de burros de carga, de herreros, de zapateros y curtidores y siempre parece decir lo mismo con las mismas palabras, de suerte que todo hombre inexperto y estúpido se burlaría de sus discursos. Pero si uno los ve cuando están abiertos y penetra en ellos, encontrará, en primer lugar, que son los únicos discursos que tienen sentido por dentro; en segundo lugar, que son los más divinos, que tienen en sí mismos el mayor número de imágenes de virtud y que abarcan la mayor cantidad de temas, o más bien, todo cuanto le conviene examinar al que piensa llegar a ser noble y bueno." (Banquete, 221e-222a).
} 
Asimismo, le confiesa a Menón: "Y ahora, qué es la virtud, yo tampoco lo sé [...] No obstante, quiero investigar contigo e indagar ( $\mu \varepsilon t \grave{a}$ бoṽ

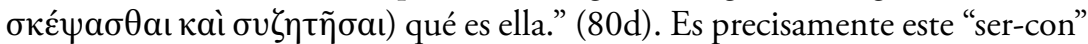

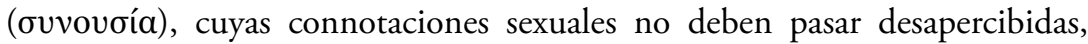
lo que caracteriza el diálogo entre Sócrates y sus interlocutores, a saber, una profunda intimidad, pues, si el diálogo es auténticamente cooperativo, la exposición mutua debe ser completa. Por esta mutua exposición en la investigación a través de un dar y recibir $\lambda$ ó $\gamma o \varsigma$, la virtud se muestra o se retira en la medida que ésta sea puesta en obra. De ahí que Sócrates pueda exhortar a Laques: "Si estás dispuesto, también nosotros resistiremos y persistiremos con firmeza en la investigación, para que la valentía misma no se burle de nosotros, de que no la hemos buscado valientemente, si es que muchas veces ese coraje en persistir es la valentía." (Laques, 194a). Y a continuación Sócrates exhorta también a Nicias: "Venga, Nicias, socorre a tus amigos que están apurados en la discusión y no encuentran la salida, si tienes alguna fuerza." (194c). Aquí se muestra claramente que la pregunta socrática, pese a la apariencia de requerir una definición o una salvación de ciertas creencias verdaderas, no apela sino a comportarse virtuosamente al discurrir sobre la virtud misma, cuya distancia ontológica es abierta por la ignorancia de ambos interlocutores, pero que sólo se hace próxima en la medida que el diálogo se vuelva cooperativo ${ }^{17}$. El diálogo, entonces, no clausura la virtud en definiciones, pues eso es precisamente lo que Sócrates niega. Más bien, se trata de alcanzar el mayor bien humano en el dialogar mismo como finita aproximación al propio cumplimiento ${ }^{18}$.

Cabe en este punto advertir la dimensión a partir de la cual el diálogo es posible. Es necesario recordar que Sócrates se enfrenta a los otros motivado por resolver el enigma del oráculo. Es precisamente esta intención de refutar al oráculo lo que, paradójicamente, constituye su más piadoso servicio a la divinidad. En efecto, por querer refutar al dios a través de refutar a los otros se descubre el diálogo cooperativo como la más propia virtud humana. De ahí que Sócrates, ante la pretensión del otro de estar

\footnotetext{
${ }^{17}$ No debe desatenderse, por otra parte, que, en la mayoría de las veces no ocurre una auténtica puesta en obra de aquello por lo cual se pregunta, sino más bien, todo lo contrario. Un ejemplo, notable, es el carácter de Menón, cuyos hábitos y tendencias arruinantes no sólo atentan contra la buena disposición de Sócrates, sino que acentúan la ambigüedad final del diálogo. Cf. Wians (2012, p. 1-24).

${ }^{18}$ Cf. González (1999, p. 133): "El proceso de llegar a ser bueno es realizado en la comunidad del diálogo filosófico. El bien no es algo que los humanos posean independientemente de, o al concluir, la investigación dialéctica y que ellos pudiesen comunicar a otros en alguna forma de enseńanza monológica. Como un proceso de devenir, nuestra bondad consiste en unirnos a otros en la búsqueda del bien.”
} 
concernido por sí mismo, afirma no dejarlo ni marcharse, "sino que le voy

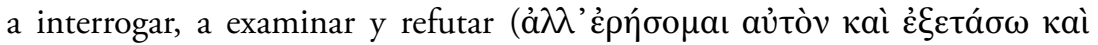

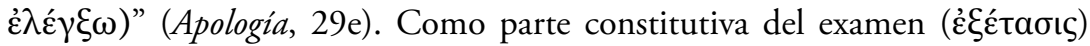

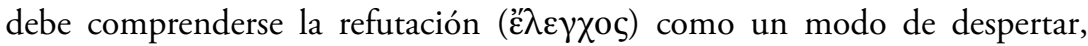
de persuadir o de avergonzar ${ }^{19}$. El modo de la refutación dependerá del interlocutor y, por lo tanto, Sócrates despertará a través de exhortaciones y advertencias, simplemente por encontrarse el interlocutor en estado de preñez, como Teeteto, o bien por ser demasiado joven, como Cármides. Persuadirá $y$, en casos extremos, avergonzará, si el interlocutor se encuentra dominado por un autoengańo, donde la ignorancia se oculta a sí misma, como en los sofistas y oradores ${ }^{20}$. En cada caso, sin embargo, el encuentro con Sócrates ha de llevar a la refutación, la cual tiene dos motivos, aunque inseparables: uno teórico y ontológico, que radica en la pregunta “¿qué es?”, y que busca $e l$ descubrimiento de la ignorancia con respecto al ser de la virtud, y uno práctico y terapéutico, que radica en la pregunta: “¿cómo vivir?”, y que busca encontrar el mejor modo posible de ejecutar la propia vida en relación a esta ignorancia. La refutación no busca un conocimiento proposicional, sino desfondar a partir de la ảлорía la confianza del interlocutor y poner al descubierto la imposibilidad de todo aseguramiento epistémico de la virtud ${ }^{21}$. La inhóspita distancia que se abre aquí entre el interlocutor y su propio ser es precisamente la condición necesaria que estimula el examen conjunto sobre el mejor modo de vivir.

\section{CoDA}

Sólo a partir del diálogo como la más propia virtud humana es posible comprender, pese a todas las advertencias, por qué en ocasiones Sócrates puede referirse a su propio ejercicio como una té $\chi v \eta$. Por una parte, Sócrates se refiere a sí mismo en el Gorgias como el único que en ese momento ejerce la auténtica

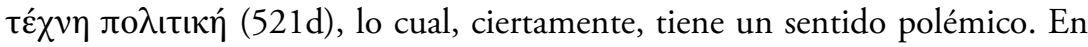

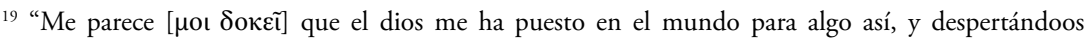

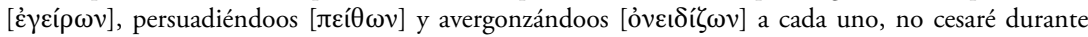
todo el día de posarme en todas partes." (Apología, 30e).

${ }^{20}$ Para una discusión sobre la relación entre la refutación y la vergüenza, sobre todo en el diálogo Gorgias, véase (TARNOPOLSKY, 2010, p. 56ss; RACE, 1979, p. 197-202; MCKIN, 1988, p. 34-48).

${ }^{21}$ Cf. Matson e Leite (1991, p. 146): "[Una] cuidadosa lectura de las exigencias de definiciones por parte de Sócrates en los diálogos investigativos, revelarán que los objetivos de Sócrates eran anticognitivistas, pues su proyecto de estimular a los ciudadanos de Atenas a la excelencia moral dependía de mostrarles que las definiciones explicitamente verbales que establecen las condiciones necesarias y suficientes para la aplicabilidad de los términos morales son imposibles."
} 
efecto, frente aquellas prácticas adulatorias e ingeniosidades complacientes de los oradores, el ejercicio dialógico se presenta como un arte angustiante, pues, como el mismo Sócrates refiere, resulta para la gran mayoría como si un médico cortara y quemara los miembros de los nińos, haciéndolos sufrir al ofrecerles bebidas amargas y obligándoles a pasar hambre y sed (521e-522a ${ }^{22}$. Por otra

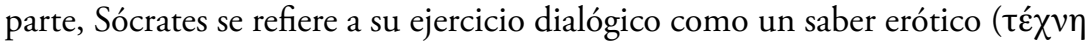

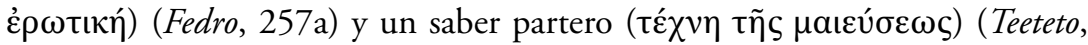
149a). Todas estas modulaciones de la té $\chi \nu \eta$ socrática convergen, a mi juicio, en la naturaleza erótica de la filosofía, la cual es clarificada en el Banquete y cuyo análisis no es posible llevarlo a cabo aquí. Bastará, sin embargo, con una indicación. En su diálogo con Sócrates, Diótima afirma que la filosofía es un

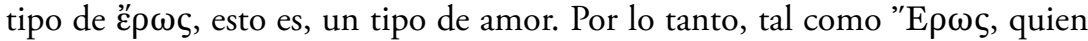
no es ni dios ni mortal, sino un gran $\delta a i ́ \mu \omega v(202 d)$, y quien, además no es amado, sino amante (204c), la filosofía tiene una doble naturaleza que se encuentra "entremedio" ( $\dot{\varepsilon} \nu \mu \varepsilon \dot{\varepsilon} \sigma \omega)$ de la ignorancia y la sabiduría. Si "E $\rho \omega \varsigma$

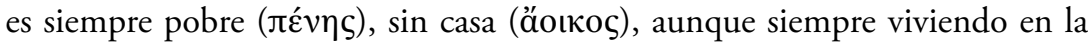

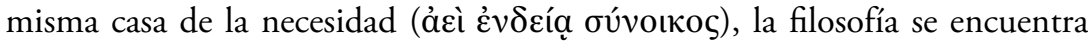
siempre en la indigente condición de la perplejidad y el asombro (ä́ropoৎ), sin

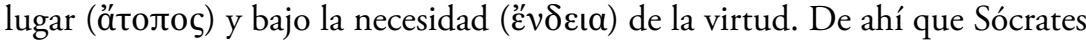
pueda decirle a Laques: "Entonces es necesario $(\delta \varepsilon \tilde{\imath})$ que esto permanezca ya

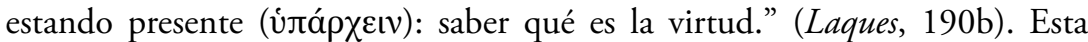
necesidad de la filosofía es resaltada con mayor urgencia en la Apología, al conminar Sócrates a sus ciudadanos a que castiguen a sus hijos si se muestran no estar preocupados de sí mismos ${ }^{23}$. Pero, así como la aporética pobreza y la necesidad constituyen la naturaleza erótica de la filosofía, también es parte de ella ese otro lado del $\delta a i ́ \mu \omega v$, a saber, "valiente, audaz y activo, hábil y terrible cazador, siempre urdiendo alguna trama, inventivo y deseoso de prudencia ( terrible hechicero, sanador y sofista" (203d). Sólo de acuerdo a esta tensión entre necesidad e industria que podemos reconocer en el mismo Sócrates, es

22 Cabe recordar la última solicitud de Sócrates a sus conciudadanos en la Apología: "Sin embargo, les pido sólo una cosa. Cuando mis hijos sean mayores, oh atenienses, castigadlos, angustiándolos

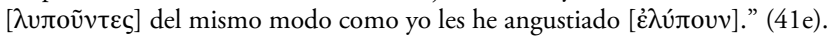

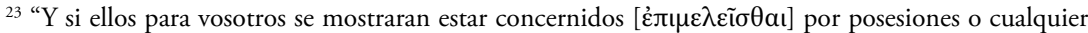
cosa más que por la ảpetí, y si ellos creyesen ser algo para sí mismos, siendo más bien nada [èàv

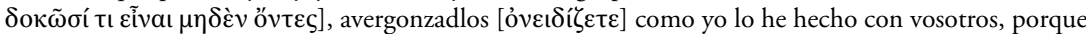
ellos no están concernidos por cosas que necesitan serlo y porque ellos piensan de sí mismos ser algo

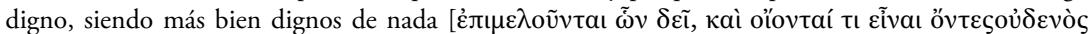
åkıoı.” (Apología, 41e). 


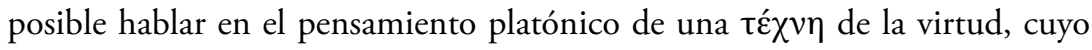
conocimiento no es epistémico ni técnico, sino, más bien, fundamentalmente erótico, pues su modo de acceder a lo conocido no es a partir de una apropiación conceptual o teórica, sino a partir de asumir la propia penuria

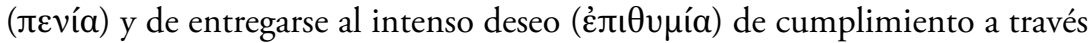
del diálogo como único camino (лópos) para confrontarnos a la distancia ontológica entre nosotros y nuestro propio ser.

DE BRAVO, C. The limits of téchne and the virtue of dialogue according to Plato. Trans/ form/ação, Marília, v. 42, n. 4, p. 9-28, Out./Dez., 2019.

\begin{abstract}
This article starts by recognizing the protective nature of téchne and its development. It is thereby possible to understand the limits of téchne based on the Socratic question of virtue. Virtue, insofar as it is not a matter analogous to the objects of téchne, requires a special access. The communitarian sense and the character of the Socratic inquiry are made plain, given dialogue as the only way of knowing virtue. Socratic dialogue discloses that virtue is never technically closed or epistemically conceptualized, but that this greatest human good is fulfilled through the joint examination of life itself.
\end{abstract}

Kerwords: Knowledge. Virtue. Dialogue. Need.

\title{
REFERENCIAS
}

ALTMAN, W. H. F. The reading order of Plato's dialogues. Phoenix, v. 64, n. 1-2, p. $18-$ 51, 2010.

ARISTÓTELES. Nicomachean Ethics. With an English Translation by H. Rackham. Cambridge, Massachusetts: Harvard University Press, 1934.

ARISTÓTELES. Ética Nicomáquea, Ética a Eudemo. Traducción de Julio Pallí Bonet. Madrid: Gredos, 1985.

ARISTÓTELES. Metafisica. Edición trilingüe por Valentín García Yebra. Madrid: Gredos, 2012.

BENSON, H. The Dissolution of the problem of the elenchus. Oxford Studies in Ancient Philosophy, Oxford: Oxford Clarendon Press,v. 13, p. 45-112, 1995.

BRANDWOOD, L. The chronology of Plato's dialogues, Cambridge: Cambridge University Press, 1990. 
BRICKHOUSE, T.; SMITH, N. The philosophy of Socrates, Colorado, U.S: Westview Press, 2000.

EVANS, M. A Partisan's guide to Socratic intellectuallism. In: TENENBAUM, S. (ed.). Desire, practical reason, and the good. Oxford: Oxford University Press, 2010. p. 6-33.

FINE, G. Inquiry in the Meno. In: KRAUT, R. (ed.). The Cambridge Companion to Plato. Cambridge: Cambridge University Press, 1992. p. 200-226.

GONZÁLEZ, F. Dialectic and dialogue: Plato's practice of philosophical inquiry. Evaston, Illinois: Northwestern University Press, 1998.

GONZÁLEZ, F. Giving thought to the good together: virtue in Plato's Protagoras. In: RUSSON, J.; SALLIS, J. (ed.). Retracing the platonic text. Evaston, Illinois: Northwestern University Press, 1999. p. 113-154.

GONZÁLEZ, F. The questioning of piety and piety of questioning in Plato's Apology. In: BOSCH-VECIANA, A.; MONSERRAT-MOLAS, J. (ed.). Philosophy and dialogue: studies on Plato's dialogues. Barcelona: Barcelona D’Edicions, 2007. p. 33-58. V. 1.

GOULD, C. Socratic intellectualism and the problem of courage: an interpretation of Plato's Laches. History of Philosophy Quarterly, v. 4, n. 3, Plato and Aristotle Issue, p. 265279, jul. 1987.

HARDY, G. Is virtue knowledge? Socratic intellectualism reconsidered. In: HARDY, G.; RUDENBUSH, G. (ed). Ancient ethics. Goettingen: V\&R Unipress, 2014. p. 141-170.

HEIDEGGER, M. Einführung in die Metaphysik. Gesamtausgabe Band 40. Frankfurt am Main: Vittorio Klostermann, 1983.

HOWLAND, J. Re-reading Plato: the problem of Platonic chronology. Phoenix, v. 45, n. 3, p. 189-214, 1991.

IRWIN, T. Plato's moral theory, the early and middle dialogues. Oxford: Clarendon Press, 1977.

IRWIN, T. Plato's ethics. Oxford: Oxford University Press, 1995.

KAHN, C. Plato and the socratic dialogue: the philosophical use of a literary form. Cambridge: Cambridge University Press, 1996.

KUBE, J. Téchne und Arete: Sophistisches und Platonisches Tugendwissen. Berlin: de Gruyter, 1969.

MATSON, W. I.; LEITE, A. Socrates' critique of cognitivism. Philosophy, v. 66, n. 256, p. 145-167, abr. 1991.

MCKIM, R. Shame and truth in Plato's Gorgias. In: GRISWOLD, D. (ed.). Platonic Writings/Platonic Readings. New York, London: Routledge, 1988. p. 34-48.

NAILS, D. The people of Plato: a prosopography of Plato and Other Socratics. Indianapolis; Cambridge: Hackett, 2002. 
NEHAMAS, A. Socratic intellectualism. In: CLEARY, J. (ed.). Proceedings in the Boston area colloquium in ancient philosophy II. Lanham, New York; London: University Press of America, 1987. p. 275-316.

NUSSBAUM, M. La fragilidad del bien: fortuna y ética en la tragedia y filosofía griega. Traducción de Antonio Ballesteros. Madrid: Visor, 1995.

PARRY, R. Plato's craft of justice. New York: State University of New York Press, 1996.

PLATÓN. Platonis Opera, Recognovit brevique adnotatione critica instruxit Ioannes Burnet, Oxonii e Typographeo Clarendoniano, Londini et Novi Eboraci apud Henricum Frowde, I (1899); II (1901); III (1903); IV (1905); V (1906).

PLATÓN. Diálogos. Madrid: Gredos, 2011. V. 1-2.

POKORNY, J. Indogermanisches etymologisches Wörterbuch. Bern: Francke, 1959. V. 3.

POSTER, C. The idea(s) of order of platonic dialogues and their hermeneutic consequences. Phoenix, v. 52, n. 3/4, p. 282-298, 1998.

RACE, W. Shame in Plato's Gorgias. The Classical Journal, v. 74, n. 3, p. 197-202, fev./ mar. 1979.

RICKLESS, S. Socrates' moral intellectualism. Pacific Philosophical Quarterly, v. 79, p. 355-367, 1998.

ROOCHNIK, D. Socrates' use of the téchne-analogy. Journal of the History of Philosophy, v. 24, n. 3, p. 295-310, jul. 1986.

SEGVIC, H. No one errs willingly: the meaning of Socratic intellectualism. Oxford Studies in Ancient Philosophy, Oxford: Oxford University Press, v. 19, p. 1-45, 2000.

SPRAGUE, R. K. Plato's philosopher king. Columbia, S.C.: University of South Carolina Press, 1976.

TARNOPOLSKY, C. Prudes, perverts, y tyrants: Plato's Gorgias and the politics of shame. Princeton, Oxford: Princeton University Press, 2010.

THESLEFF, H. Platonic chronology. Phronesis, v. 34, n. 1, p. 1-26, 1989.

VLASTOS, G. Socratic knowledge and Platonic "pessimism". The Philosophical Review, v. 66, n. 2, p. 226-238, abr. 1957.

VLASTOS, G. Socratic studies, Cambridge: Cambridge University Press, 1994.

VLASTOS, G. The paradox of Socrates. In: GRAHAM, W. (ed.). Socrates, Plato and their Tradition: studies in greek philosophy. Princeton, New Jersey: Princeton University Press, 1995. p. 3-18. V. 2.

WIANS, W. Virtue, practice, and perplexity in Plato's Meno. Plato: The Internet Journal of the International Plato Society. Plato 12, 2012. Disponible en https://digitalis-dsp. uc.pt/bitstream/10316.2/42172/3/Virtue\%2C_practice\%2C_and_perplexity.pdf. Acesso em: 15 ago. 2018 . 
WOODRUFF, P. The skeptical side of Plato's method. Revue Internationale de Philosophie, v. 40, n. $156 / 157$ (1/2), p. 22-37, 1986.

Recebido: 28/01/2018

Aceito: $15 / 10 / 2018$ 
DE BRAVO, C. 